\title{
POTENCIALIDADES E DESAFIOS PARA A GESTÃO REGIONAL EM \\ SAÚDE: REFLEXÕES A PARTIR DA DINÂMICA DOS ESPAÇOS \\ COLEGIADOS
}

\section{REGIONALIZATION IN HEALTH ANDCOLLEGIATE/COMMISSIONS \\ MANAGEMENT: DYNAMICS, CONTRIBUTIONS, POTENTIALITIESANDCHALLENGES}

\author{
Maria Rita Nery Santos Souza ${ }^{1}$ \\ Mariluce Karla Bomfim de Souza ${ }^{2}$
}

\begin{abstract}
Resumo: Os espaços colegiados de gestão configuram-se como instâncias de pactuação e negociação no contexto da regionalização da saúde. Objetivo: discutir as características, potencialidades e desafios do colegiado/comissão de gestão regional para o fortalecimento da regionalização. Trata-se de estudo exploratório, descritivo e de abordagem qualitativa, realizado através de entrevistas com gestores e análise dos conteúdos dos relatos. Os resultados evidenciaram que os colegiados/comissões se caracterizam como instrumentos para regionalização, instâncias de cogestão solidária e são relevantes na conformação das redes, entretanto, ainda encontra entraves para a sua operacionalização. $\mathrm{O}$ estudo mostrou que limites para a concretização da regionalização, indicando a necessidade por avanços para a superação dos desafios decorrentes desse processo.
\end{abstract}

Palavras-chave: Regionalização; Gestão em Saúde; SUS.

\begin{abstract}
Collegial management spaces are configured as instances of negotiation and pacing in the context of health regionalization. Objective: to discuss the characteristics, potential and challenges of the collegiate / regional management commission to strengthen regionalization. It is an exploratory, descriptive and qualitative approach, conducted through interviews with managers and analysis of the contents of the reports. The results showed that the collegiate / commissions are characterized as instruments for regionalization, instances of joint management and are relevant in the conformation of the networks, however, it still finds obstacles to its operationalization. The study showed that limits to the realization of regionalization, indicating the need for advances to overcome the challenges arising from this process.
\end{abstract}

Keywords: Regionalization; Health Management; SUS.

\section{Introdução}

Após mais de 20 anos de implantação do Sistema Único de Saúde são inegáveis os avanços para que a saúde seja direito de todos e dever do Estado, onde todos devem ter acesso universal e igualitário às ações e serviços para sua promoção, proteção e

\footnotetext{
${ }^{1}$ Enfermeira especialista em Oncologia pelo Instituto de Medicina Integral Fernando Figueira (IMIP). Recife. Pernambuco. Brasil. E-mail: marianery@outlook.com

${ }^{2}$ Doutora em Saúde Pública. Docente do Instituto de Saúde Coletiva. Departamento de Saúde Coletiva da Universidade Federal da Bahia (UFBA). Salvador. Bahia. Brasil. E-mail: marilucejbv@yahoo.com.br
} 
recuperação (BRASIL, 1988). No entanto persistem as dificuldades para ampliar a oferta e a cobertura das ações e serviços de saúde, bem como para qualificar a assistência persistem, ainda que o SUS tenha alcançado inegáveis.

Dentre as lacunas ainda existentes, a intensa fragmentação das ações e serviços do SUS para a oferta do cuidado integral à saúde expõe a necessidade de articulação e cooperação entre os sistemas municipais de saúde (SANTOS; GIOVANELLA, 2014) que teve início com o processo de descentralização com institucionalização das Comissões Intergestores Tripartite e Bipartite, criando dessa forma um sistema decisório compartilhado pelas diferentes instâncias federativas, além de impulsionar a política de municipalização, estabelecendo assim o pleno exercício do poder municipal, dando ênfase ao processo de fragmentação do SUS (BRASIL, 2006a)

Para a operacionalização da descentralização, o Pacto de Gestão, enquanto política de gestão e dimensão do Pacto pela Saúde, assumiu a regionalização enquanto função de eixo estruturante que orienta as ações e serviços de saúde e os processos de negociação e pactuação entre os gestores (BRASIL, 2006b). Para Dourado e Elias (2011), a regionalização procede da necessidade basilar de integrar seus componentes para garantir a efetivação do direito à saúde no País. Pela natureza federativa do sistema, isso só pode ser realizado mediante arranjos institucionais estabelecidos entre os entes federados.

Para viabilizar a implementação da regionalização, a NOAS propõe a criação das regiões de saúde, as quais devem funcionar como base territorial de planejamento da atenção à saúde, entretanto, não necessariamente eles estão divididas conforme a administração política do estado, sendo consideradas como critérios nesta divisão, as especificidades, peculiaridades da disponibilidade dos serviços de saúde dos municípios que comporão a região de saúde, assim como as características demográficas, socioeconômica, sanitária, entre outras (BRASIL, 2001, 2002).

$\mathrm{Na}$ tentativa de minimizar as fragilidades da regionalização, a partir do Pacto de Gestão, em 2006, foram criados os Colegiados de Gestão Regional (CGR) como um dos instrumentos para a concretização da governança regionalizada, os quais a partir da publicação do Decreto $\mathrm{n}^{\mathrm{o}} 7.508$ de 2011 passaram a ser chamados de Comissão Intergestores Regional (CIR) que funcionam como instâncias permanentes de negociações, pactuações e cogestão solidária e cooperativa entre gestores dos espaços regionais definidos no Plano Diretor Regional (PDR). 
Lima et al., (2012) aborda que os Colegiados mantêm correlação com processos de regionalização previamente existentes, sendo influenciados pela prática de revisão e atualização do desenho regional adotado no âmbito estadual.

Para Cecílio (2010), o colegiado de gestão não é apenas um arranjo burocráticoadministrativo, deve ser pensado como um arranjo institucional, assumindo um caráter fortemente político, pois se constitui em um espaço onde os temas de autoridade, controle de decisão e poder sempre se fazem presentes, mais ou menos de forma explícita.

As Comissões Intergestores Regionais são instâncias formadas pelos gestores de saúde do conjunto de municípios integrantes da Região de Saúde e por representantes do estado com capacidade de provisão de serviços de saúde em diferentes níveis de atenção. As decisões neste espaço colegiado são sempre feitas por consenso, pressupondo o envolvimento e comprometimento dos gestores (BRASIL, 2009; SILVEIRA FILHO et al., 2016).

Viana, Lima e Ferreira (2010) afirmam que o CGR, atual CIR, permite a identificação de problemas, definição de prioridades e de soluções para o processo de organização das redes de assistência regionalizada, fazendo deste, um instrumento poderoso para a constituição de objetivos compartilhados e resolutividade para as necessidades de saúde da população. Expõem ainda que esse representa uma inovação da política de saúde, pois cria um canal permanente de negociações e decisão intergovernamental, tendo regras definidas e funcionamento estável, preenchendo o que é chamado de "vazio" da governança regional.

Dada a relevância das CIR como ferramenta no processo de regionalização e governança regional (SOUZA; SOUZA, 2017), surgiram questionamentos sobre o processo de implantação e dinâmica dos espaços colegiados gestores regionais e as suas contribuições e desafios para a gestão e fortalecimento da regionalização.

Delineia-se, então, como objetivo desse estudo: Discutir as características, potencialidades e desafios de Colegiado de Gestão Regional, atual CIR, para o fortalecimento da regionalização em saúde.

\section{Aspectos Metodológicos}

Trata-se de um estudo de abordagem qualitativa, natureza descritiva e caráter exploratório. Para Gaskell (2008) a pesquisa qualitativa tem por finalidade conhecer a variedade de opiniões, as diferentes reproduções sobre o assunto em questão, bem como 
fornecer os dados básicos para o desenvolvimento e a compreensão detalhada de forma subjetiva, em contextos sociais específicos.

Caracteriza-se também como um estudo descritivo que proporciona a descrição das características de determinada população ou fenômeno ou, então, o estabelecimento de relações entre variáveis, e de caráter exploratório que proporciona certa familiaridade com o problema, assim como aprimora ideias e descobertas de intuições (GIL, 2002).

No momento da coleta para este estudo, o colegiado de Santo Antônio de Jesus (CGR/SAJ) estava em funcionamento com reuniões mensais nos municípios alternadamente, conforme cronograma estabelecido em plenárias.

A definição dos critérios para delimitar o universo dos sujeitos que participarão da pesquisa é algo primordial, interferindo diretamente na qualidade das informações a partir das quais será possível construir a análise e chegar a uma compreensão ampliada do problema delineado (DUARTE, 2002). Foram convidadas a participar dessa pesquisa, todas as pessoas que ocupam cargos formais de gestão na Secretaria Municipal de Saúde de um município baiano (secretário de saúde, diretores, coordenadores), além da secretária executiva do Colegiado de Gestão/Comissão Intergestores Regional desta Região de Saúde. De acordo com o organograma da Secretaria Municipal são 20 (vinte) os gestores que representam a gestão municipal (2009-2012), além do gestor estadual do CGR/CIR. Entretanto, desse total de sujeitos, foram entrevistados 10 (dez). Foram encontradas dificuldades para o agendamento e aceite de participação por conta das mudanças ocorridas na gestão após período eleitoral.

Neste estudo, os participantes entrevistados estão identificados através da letra 'E' seguida por uma sequência numérica (01 a 10), ou seja, os gestores estão identificados de E01 a E10, como modo de garantir o anonimato dos mesmos, conforme proposto no Termo de Consentimento Livre e Esclarecido. A participação foi voluntária, sendo informado aos entrevistados que a qualquer momento eles poderiam desistir da pesquisa, assim como alterar ou retirar as informações referentes à entrevista.

A coleta de dados configura-se numa peça importante para o desenvolvimento da pesquisa, influenciando no padrão de qualidade das informações colhidas. Neste estudo foram utilizadas duas técnicas de coleta: a entrevista, para a produção de dados primários; e a análise documental, para os dados secundários.

A técnica de entrevista, segundo Manzini (1991) se focaliza em um determinado tema sobre o qual é confeccionado um roteiro específico composto por perguntas principais e outras complementares inerentes às circunstâncias momentâneas. Para este 
autor, a entrevista semi-estruturada possibilita a imersão de informações de maneira livre, ou seja, as informações colhidas não estarão condicionadas a uma padronização de alternativas.

Outro fator relevante é que através desta técnica, o pesquisador mantém-se presente e atuante no processo da coleta das informações, e assim visualiza sobre a ótica dos gestores as experiências relacionadas ao processo de regionalização e relevância dos espaços de cogestão solidária e pactuação (CGR/CIR).

O roteiro de entrevista utilizado para esta pesquisa inclui questões sobre aspectos profissionais e experiência (s) dos entrevistados com a gestão em saúde. Interroga sobre a inserção e atuação da gestão municipal no CGR/CIR, assim como sua relevância no desenvolvimento do processo de regionalização. E, destaca também a implantação do CGR/CIR, bem como, sua operacionalização, reflexos, contribuições e desafios (SOUZA; SOUZA, 2017).

A realização das entrevistas teve início no mês de dezembro de 2012, após apreciação e aprovação do projeto de pesquisa (parecer $n^{\circ} 174.183$ ) pelo Comitê de Ética em Pesquisa da Universidade Federal do Recôncavo da Bahia (CEP/UFRB), porém só foram finalizadas no mês de junho de 2013 em decorrência das alterações na ocupação dos cargos decorrente do resultado das eleições municipais; de modo que o relatório desta pesquisa apenas foi concluído no início de 2014.

Para a produção dos dados secundários foi realizada a análise documental das Atas do Colegiado de Gestão de Santo Antônio de Jesus - Bahia, Brasil dos anos de 2011 e 2012, totalizando 17 atas disponíveis eletronicamente no site da Diretoria de Programação e Desenvolvimento da Gestão Regionalizada (DIPRO). Escolheram-se as atas destes anos (2011 e 2012) em função da disponibilidade online à época da coleta, sendo um critério de exclusão os demais anos. As atas foram identificadas pela letra ' $D$ ' seguida por uma sequência numérica de 01 (um) a 17 (dezessete), logo foram identificadas de D01 a D17.

Após a coleta dos dados, os mesmos passaram por análise e interpretação com base na análise de conteúdo de Bardin (2009). Foi utilizada nesta pesquisa a análise temática, onde o conceito central é o tema, comportando um feixe de relações que pode ser graficamente apresentado através de uma palavra, uma frase, um resumo (BARDIN, 2009; MINAYO, 2006).

Para a análise de conteúdo, as duas investigadoras cumpriram as seguintes fases ou etapas: pré-análise; decomposição do material; e, ordenação dos dados, inferência e interpretação. Na primeira etapa, a pré-análise, os materiais (entrevistas e atas) foram 
organizados, sendo realizadas sucessivas escutas para garantir a fidedignidade nas transcrições das entrevistas e assim, através de repetidas leituras buscou-se identificar convergências e divergências no conteúdo das entrevistas, buscando ter uma visão do conjunto, as quais foram destacadas separadamente de acordo com cada entrevistado.

Na segunda fase, referente à análise propriamente dita, foi realizada a exploração do material e a classificação dos dados através de uma leitura compreensiva do conjunto do material selecionado. Assim, foi possível o desenvolvimento de uma visão do conjunto, sendo apreendidas as particularidades do conjunto do material a ser analisado, elaborando pressupostos iniciais que serviram de baliza para a análise e a interpretação do material, escolhendo formas de classificação inicial, e determinando os conceitos teóricos que orientaram a análise (GOMES, 2010).

Este processo permitiu a definição de três categorias analíticas para o desenvolvimento da síntese interpretativa, a saber: Processo de implantação e dinâmica do colegiado gestor regional/CIR; Contribuições do colegiado gestor para o fortalecimento das redes regionalizadas; e, Potencialidades e desafios do colegiado de gestão regional. Destaca-se a não utilização de programas de software como apoio para esta categorização. Além dos trechos das entrevistas que complementam a categorização, foi realizada a leitura das atas do Colegiado de Gestão (CGR/SAJ), dando subsídios na análise de cada categoria.

$\mathrm{Na}$ terceira etapa, foi realizado o tratamento dos dados, a inferência e interpretação. Para Gomes (2010) a inferência é uma fase intermediária entre a descrição, mencionada como a enumeração das características do texto, sendo resumida após tratamento analítico; e interpretação. Nesta etapa elaborou-se uma síntese interpretativa, a qual para Minayo (2009) é descrita como uma confrontação entre as informações obtidas e as informações existentes, e assim a elaboração de uma redação que dialogue temas com objetivos, questões e pressupostos da pesquisa, originando o capítulo sobre análise e discussão dos resultados.

\section{Análise e Discussão dos Resultados}

\subsection{Categoria 1: Processo de Implantação/Dinâmica de um Colegiado Gestor}


À realização das entrevistas, os gestores foram questionados sobre o processo de implantação do CGR/SAJ e sobre sua dinâmica de funcionamento. No que diz respeito à implantação, o depoimento abaixo trouxe:

[...] o processo de implantação do colegiado foi muito puxado do nível federal e estadual, então a implantação veio já de um terreno fértil porque tava fomentando a regionalização [...] então esse processo de formação do colegiado que é mais uma instância de negociação, antes da CIB que é os estados e municípios conversando lá a nível central, a gente tem o CGMR a nível local e loco regional. O processo se deu da seguinte forma: os gestores se encontravam, mas a própria DIRES (Diretoria Regional de Saúde) já chamava os gestores de forma regular para reunir e discutir os processos, com o CGMR [...] se legitimou esses fatos, se criou coordenador e o vicecoordenador, uma agenda de reuniões [...] (E02).

[...] veio através de uma portaria específica, criando esses colegiados, e esses eram delimitados por microrregião [...] esse processo de formação começou de forma que deu autonomia aos municípios no processo de regionalização. (E09)

[...] a gente fez uma reunião com os gestores, conseguimos formar. São 23 municípios (E10).

A partir da definição do Plano Diretor de Regionalização (PDR) e conformação das regiões de saúde, Schneider et al., (2009) reafirmam a importância da constituição do colegiado/comissão intergestores, onde todos os gestores municipais de saúde e também os representantes do(s) gestor(es) do estado devem participar, e assim possibilitar o desenvolvimento de um planejamento do SUS regional mais coerente com a realidade.

Para que o CGR seja reconhecido, os secretários municipais de saúde da Região de Saúde e os representantes estaduais, indicados pela Secretaria Estadual de Saúde, para compor este colegiado, realizam a primeira reunião e, observadas as diretrizes pactuadas na CIB, elaboram a ata de constituição do Colegiado que após assinada por todos os presentes é enviada à CIB. A CIB reconhecerá o CGR mediante cópia da ata da constituição com as assinaturas de todos os secretários municipais de saúde da Região de Saúde correspondente e dos representantes do gestor estadual. Após o reconhecimento do CGR, a CIB envia à CIT informações em formulário próprio definido na Portaria GM/MS $\mathrm{n}^{\circ} 2.691 / 2007$ (BRASIL, 2007).

A forma de operacionalização do CGR, atualizada e substituída em 2011, a partir do Decreto 7508/2011, no qual o colegiado passa a ser chamada Comissão Intergestores Regional (CIR), além de alterar os termos de macro/microrregião de saúde, passando a ser denominada região de saúde, é fundamental para a consolidação dos mesmos enquanto instâncias de papel decisório (BRASIL, 2011a). Tais colegiados ou comissões representam um mecanismo para a aceleração da regionalização de assistência, principalmente através das conformações das redes assistenciais de saúde (RAS). 
Como já mencionado, a CIR representa um mecanismo para a aceleração da regionalização de assistência, principalmente através das conformações das redes assistenciais de saúde (RAS). No entanto, as comissões passam por um processo de implantação/implementação gradual com dificuldades de consolidação deste espaço dentro do que se propõe, que podem ser explicadas, segundo Viana, Lima e Ferreira (2010) pela "forte ingerência do poder político eleitoral [...] em determinadas regiões, e pesadas heranças centralizadoras em alguns estados da federação". Também acrescentam outras razões que justificam tais dificuldades, como a concentração/centralização de recursos e tecnologias em algumas regiões, chamadas de "fatores estruturais que se ligam ao perfil socioeconômico de uma determinada região, os indicadores sociais e a capacidade instalada da rede de serviços de saúde e seu grau de complexidade”.

Quanto à dinâmica de funcionamento do CGR/SAJ, os participantes trouxeram sobre o modo como se dá as pactuações nas reuniões, assim como o cronograma destas. O trecho abaixo ilustra tal afirmação:

[...] O regimento diz que o máximo de tempo de intervalo tem que ser dois meses [...], mas aqui eles deliberaram que fariam mensais [...] uma iniciativa foi positiva para o colegiado, eles fazem um cronograma que as reuniões são itinerantes $[\ldots](\mathrm{E} 02)$.

De acordo com o regimento interno do Colegiado de Gestão Regional (CGR), instituído pela Resolução CIB n ${ }^{\circ} 143$ de 09 de outubro de 2007, as reuniões ocorrerão de dois em dois meses. Entretanto, neste colegiado ocorrem mensalmente, como pode ser constatado nas atas (D01 a D17) do CGR (BAHIA, 2007).

Sobre a dinâmica do CGR/SAJ, o fragmento abaixo refere:

[...] São 23 municípios, sempre a gente teve quórum [...] passaram a ser itinerante, a gente ia a cada município que permitia a gente 'ta' conhecendo a realidade local do sistema de saúde local. As dificuldades que os gestores enfrentavam, e pra gente ficou mais fácil 'ta' aprovando os projetos daquele município no colegiado. Sempre foi excelente, que são 23 municípios e pra ter quórum a gente precisa ter 14 e geralmente a gente trabalhava com 16 . E a gente percebia que em muitas regiões os municípios tinham 9,6 e não cumpriam quórum, não conseguia quórum. E aqui conseguiu[...]. Agora, ultimamente, como mudou muito as gestões, temos aí ainda o início né, de um novo processo que também tem sido solidificado, que conseguiu instalar a CIR, que agora é CIR, que é Comissão Intergestores Regional e a gente tem conseguido funcionar assim, são bem atuantes (E10).

Através das atas do CGR é possível observar que do total de reuniões agendadas (17) no período dos anos de 2011 e 2012, em 35,3\% não houve quórum, e que nas demais o quórum fica em torno do mínimo esperado, não estando em conformidade com o que foi relatado por E10. Faz-se necessário abordar sobre a participação do gestor estadual, 
do total de reuniões apresentadas nas atas, em que se constatou a participação em 41,2\% desses encontros.

Apresentar essas informações é relevante para evidenciar a representatividade dos gestores das duas esferas de governo (estadual e municipal) na instância colegiada, pois de acordo com Kishima, Zanatta e Júnior (2012) a participação destes nessas reuniões pode ser uns dos indicadores importantes para avaliar a legitimação desse espaço de gestão compartilhada.

A participação dos gestores nestas reuniões é de alta relevância, pois nestas serão discutidas linhas de prioridades comuns aos municípios da região de saúde; implantação e implementação de redes de assistência e outras pactuações, sendo um processo indispensável para o fortalecimento da gestão compartilhada e minimizar as fragilidades no planejamento SUS para estes municípios, como ilustrado por E09:

[...] reunir gestores num espaço com regularidade bimensal, ou mensal, mesmo que alguns faltem, mas você consegue trazer isso; essa possibilidade de reunião você consegue resolver alguns problemas a nível regional que não precise levar a nível estadual; então desde pactuação, desde deliberação de algumas ações [...] para deliberar algumas coisas para alguma região, ela precisa pedir autorização, tem que passar por aprovação no colegiado [...] (E09).

Assis et al., (2009) afirmam que nas reuniões do CGR/CIR são deliberadas e decididas as questões de forma consensual. Sobre isso, E10 refere que as decisões no CGR são feitas consensualmente, conforme trecho abaixo.

[...] No Colegiado [...] as decisões são todas por consenso, [...] e em alguns momentos a gente teve alguns encaminhamentos pro Estado que de certa forma teve um choque, conflito de ideias, de condições (E10).

Os regimentos internos (CIR e CGR) orientam que os aspectos operacionais, financeiros e administrativos sejam pactuados por consenso. Caso não haja consenso por duas reuniões consecutivas, constituindo-se em caso de impasse insuperável, o assunto deve ser submetido à Comissão IntergestoresBipartite (CIB) e esta atuará como instância de recurso para os municípios (BAHIA, 2012).

Outro aspecto importante sobre a dinâmica de funcionamento dos CGR/CIR é o financiamento dos mesmos. Delziovo (2012) menciona que a transferência de recursos financeiros para os CGR está regulamentada por portaria ministerial. O valor anual é repassado do governo federal ao Fundo Estadual de Saúde.

Os recursos são direcionados para uma conta da sede da microrregião (atual região de saúde) [...] então os recursos vem para uma conta específica [...]. Todas as decisões são pautadas e deliberadas em colegiado [...] (E10). 
A dinâmica do CGR tem sido marcada pelas alterações recentes para CIR, que implicam nas mudanças na organização e coordenação desses fóruns, que após a publicação da nova resolução fica sob responsabilidade direta do estado.

\title{
3.2 Categoria 2: Contribuições do Colegiado/Comissão Intergestores para o
}

\section{Fortalecimento das Redes Regionalizadas}

Na perspectiva da regionalização, a constituição das redes regionalizadas de saúde tem por objetivo oferecer atenção à saúde de forma contínua, integral e qualificada. $\mathrm{O}$ avanço no processo de descentralização com enfoque na municipalização e gestão descentralizada, ao longo dos anos 90, propiciou a organização e a articulação das redes de serviços (PAIVA et al., 2010). Mendes (2010) enfatiza a implantação das redes de atenção à saúde (RAS) como peça relevante para superar o sistema fragmentado vigente. A construção dessas redes exige planejamento, cogestão e financiamento intergovernamentais voltados ao desenvolvimento de políticas de saúde que sejam adaptadas às realidades de cada espaço regional (BRASIL, 2008).

As redes de atenção à saúde são referidas por Lavras (2011, p. 872) como:

\begin{abstract}
Arranjos organizativos de unidades funcionais de saúde, pontos de atenção e apoio diagnóstico e terapêutico, onde são desenvolvidos procedimentos de diferentes densidades tecnológicas que, integrados através de sistemas de apoio e de gestão, buscam garantir a integralidade do cuidado.
\end{abstract}

De acordo com o decreto $\mathrm{n}^{\mathrm{o}} 7.508 / 2011$ a RAS se inicia e se completa a partir das comissões intergestores, mediante referenciamento do usuário na rede regional e interestadual. A atenção primária à saúde (APS) se configura como a primeira porta de entrada às ações e aos serviços de saúde nas redes de atenção, devendo ordenar o acesso às ações e aos serviços de saúde e coordenar o cuidado.

Os relatos das entrevistas e algumas atas trouxeram um exemplo factível de operacionalização de um projeto de rede regionalizada, a saber: o SAMU Reconvale.

Os principais processos que a gente vê a regionalização acontecer foi o SAMU regional Reconvale [...] Esse foi um processo de planejamento compartilhado muito interessante, onde a gente pode ver nitidamente o processo de regionalização (E02).

[...] Pactuação do Plano Regional de Urgência e Emergência - SAMU regional no Colegiado ampliado de Cruz das Almas e Santo Antônio de Jesus, enfatizando a necessidade de aprovação da rede prioritária como Região Metropolitana Ampliada [...]. Apresentação dos componentes do projeto, informando os critérios [...]. Apresentação da proposta de ampliação do SAMU, com o objetivo de atingir $100 \%$ de cobertura da população (D07; D14). 
Por meio da portaria $\mathrm{n}^{\mathrm{o}}$ 1.600, de 07 de julho de 2011, a Política Nacional de Atenção às Urgências foi reformulada e instituída a Rede de Atenção às Urgências. Correlacionando com o que foi exposto por E02 e constatado em D07 e D14, a Rede de Atenção às Urgências tem a finalidade de articular e integrar todos os equipamentos de saúde, objetivando ampliar e qualificar o acesso humanizado e integral aos usuários em situação de urgência e emergência nos serviços de saúde (BRASIL, 2011b).

Sobre o projeto SAMU Regional Reconvale, evidenciado através das entrevistas e atas do CGR/CIR, Daltro e Barbosa (2012) afirmam que este projeto visa uma ampliação da cobertura para os demais municípios das duas microrregiões, por meio do espaço deliberativo dos respectivos Colegiados de Gestão Microrregionais (CGMR/CIR).

D01 e D02 também ilustram esse processo de conformação de redes de assistência associada ao processo de regionalização e de suas estratégias, através do processo de implantação da Rede Cegonha na região de saúde. Essa informação encontra respaldo no trecho abaixo:

Pactuação do Plano de Ação da Rede Cegonha [...] Apresentação da Rede Cegonha, inclusive com apresentação da Matriz de atividades estratégicas por Ação e Componentes para a construção do Plano de Ação da Rede Cegonha [...] Apresentação das diretrizes e critérios do desenho da Rede Cegonha (D01; D02).

A Rede Cegonha foi instituída no âmbito do Sistema Único de Saúde (SUS) através da portaria $\mathrm{n}^{\mathrm{o}} 1.459$, de 24 de junho de 2011. Ela consiste numa rede de cuidados que visa assegurar à mulher o direito ao planejamento reprodutivo e à atenção humanizada à gravidez, ao parto e ao puerpério, bem como à criança o direito ao nascimento seguro e ao crescimento e ao desenvolvimento saudáveis (BRASIL, 2011c). A Rede Cegonha apresenta o mesmo processo de operacionalização para a implantação da Rede de Atenção às Urgências, ou seja, o processo de conformação dessas redes apresenta as seguintes fases: Adesão e diagnóstico, Desenho Regional da Rede Cegonha, Contratualização dos Pontos de Atenção, Qualificação dos componentes e Certificação.

Embora o processo de regionalização tenha facilitado a implantação/implementação de redes de assistência, os gestores ainda encontram empecilhos na pactuação destas em instâncias de gestão compartilhada. Os trechos de E02 complementam essa informação:

[...] não é fácil construir projeto regional, por tudo isso, planejamento político, capacidade técnica, muitas vezes alguns municípios ficaram atrás porque não tinha capacidade técnica para construir a unidade, para montar sua equipe, para fazer a seleção dos profissionais. [...] A gente tem várias questões na compra 
de serviços que são mais caros, tem isso na manutenção da Central de Regulação do SAMU, porque é um hospital, tem médico todo dia que é um serviço caro porque tem médico 24 horas por dia, tem toda uma dificuldade, porque além do que o Ministério da Saúde coloca, você tem que colocar uma contrapartida e essa contrapartida vem de Santo Antônio de Jesus. Os municípios, às vezes, tão se beneficiando e não percebem que podem ajudar [...] são dilemas e dificuldades que todo o processo de regionalização, todas as redes e tudo que for seguir por aí vai enfrentar (E02).

\subsection{Categoria 3: Potencialidades e Desafios dos Espaços Colegiados de Gestão}

Mesmo com seu caráter inovador e suas competências legais, os CGR/CIR ainda encontram desafios a superar para que possam exercer todas as suas potencialidades enquanto estratégia de reorganização do processo de regionalização da assistência.

A partir das análises das entrevistas foram encontrados relatos sobre indução estadual no processo decisório do CGR/CIR, o que por sua vez, pode interferir na autonomia municipal. O trecho de E02 traz sobre as alterações da representação estadual com o estabelecimento da CIR em que o diretor e um técnico da DIRES assumem a representação estadual na CIR como membros efetivos, junto a outro gestor de saúde oriundo da Secretaria de Saúde do estado que assumirá a coordenação da CIR.

O representante estadual por ele, no regimento já ter vindo no pacote que ele seria o coordenador [...]; então a DIRES, ou seja, o estado já entrou com o papel de chefe daquele espaço que seria o espaço do colegiado, de cogestão do sistema, então o representante estadual de alguns municípios e colegiados, eles tem o processo de chefe e saltam tudo [...] (E02).

O trecho de E09 reforça o que foi relatado por E02, ao trazer sobre as dificuldades encontradas para que as metas do CGR/CIR sejam alcançadas. Ao referir sobre a indução estadual, não houve mudança positiva neste sentido com a alteração para as CIR, visto a ocupação do diretor da DIRES neste espaço. Há que se destacar que o cargo de direção das DIRES é indicado pelas Secretarias Estaduais de Saúde, sendo assim, cargos por indicação política.

[...] normalmente era muita pauta da SESAB [...] a gente acabava deixando a pauta do colegiado pra depois para dar oportunidade, mas isso passou a ser com uma frequência tão grande que atrapalhou as demandas do colegiado [...] (E09).

A discussão sobre a relação do estado com as Regiões de Saúde permitiu refletir sobre a relação entre os níveis de gestão do SUS e a ineficiência das instâncias e instrumentos de gestão regional. Ianni et al., (2012) resgatam essa perspectiva relatando sobre a dinâmica autárquica no processo de descentralização/regionalização atual, a qual aponta que as diretorias regionais de saúde possuem fragilidades tanto técnicas quanto 
políticas para exercer sua função precípua de articulação regional e apoio técnico aos municípios. Apontaram, ainda, que tais diretorias podem exercer controle no espaço do CGR/CIR, fazendo prevalecer o caráter vertical da relação estado/municípios. Atualmente, no estado da Bahia, as DIRES foram extintas e então criados os Núcleos Regionais de Saúde.

Barrios (2009) corrobora com Vasconcelos (2005) ao relatar que a institucionalização do CGR/CIR gerou os conflitos próprios das relações interfederativas do governo estadual e municipal, tendendo a favorecer aqueles atores que historicamente detém o maior poder, como é o caso do gestor estadual, como observado a partir das análises das entrevistas.

Barrios (2009) complementa que o CGR/CIR apresenta fragilidades na constituição das suas pautas, justificada pela preponderância estadual, que encontra subsídios para tal no próprio formato do Colegiado, pela definição, em especial, de sua coordenação que tem como membro nato a gestão estadual, remetendo a ideia de indução estadual como mecanismo fragilizador.

O trecho de E09 faz referência a essa indução estadual como fragilidade do CGR/CIR ao citar o funcionamento nesses fóruns após mudança de CGR para CIR, afirmando que os coordenadores estaduais não conhecem a realidade locorregional o que dificulta a resolutividade dos entraves comuns aos municípios.

[...] os municípios não têm mais função de deliberação nos colegiados, quem tem isso é só a DIRES, eu acho que veio a tornar falho, porque quem faz a gestão são os municípios [...] (E09).

Sobre a perspectiva de indução estadual, Solla contribui com Barrios (2009), ao relatar que:

[...] em muitas situações, a desigualdade do poder entre as esferas de gestão induz fortemente a decisões que privilegiam interesses dos gestores estaduais sobre os municipais, com resultados por vezes inadequados ao processo de descentralização (SOLLA, 2006, p. 341).

Retomando aos aspectos que fazem do CGR/CIR um espaço permanente de gestão compartilhada, foram analisados os trechos sobre as características positivas, designadas como potencialidades.

Têm os aspectos positivos, primeiro por que é um fórum que capacita o gestor. [...] são espaços que possibilitam os gestores se apropriar. [...] outra questão é que as próprias políticas de governo não permitem mais fazer os projetos de forma individualizada, você tem que está articulado, de forma regional [...] (E02). 
Acredito que são as trocas de experiências. Isso é muito bom. A gente normalmente participa dos cursos organizados pelo Colegiado e a gente tem trocas de experiências com outros municípios (E06).

Ao fazer alusão sobre as trocas de experiência como potencialidade do CGR/CIR, retoma-se a essa ideia como um desejo de que esses espaços possam ser conduzidos de modo mais coletivo, compartilhado entre os entes municipais e estadual, que possibilitem aos gestores pensarem em processos políticos que permitam instituir arranjos com potencialidade para produzirem novos desenhos e novas direcionalidades no que tange à regionalização em saúde (MERHY, 2002 apud BARRIOS, 2009).

Ao refletir sobre processos políticos e gestão de saúde, E09 faz referência a um desafio para o fortalecimento dos CGR/CIR,

[...] o processo de gestão, um cargo político, [...] quanto mais se muda os gestores no município, $[\ldots]$ isso era um dificultador, porque quem chegava novo no colegiado ficava um pouco perdido até se adequar, a não ser se ele tivesse sido gestor em outro município [...] (E09).

Reforçando o que foi exposto por E09, Kishima, Zanatta e Júnior (2012) referem que as trocas de gestores municipais com frequência baseada em critérios apenas políticos e não técnicos contribuem para uma precária qualificação técnica desses gestores, prejudicando o aprofundamento em discussões comuns nas reuniões dessas instâncias das regiões de saúde, comprometendo de algum modo o processo de regionalização e a constituição de projetos e redes regionalizadas de atenção à saúde.

\section{Considerações finais}

Este estudo revelou lacunas que comprometem a operacionalização das comissões intergestores regional e apontou desafios ainda existentes para a regionalização dos serviços de saúde. Portanto, a discussão dos achados evidenciou a complexidade para a articulação e cogestão entre os municípios, comprometendo assim, o fortalecimento do processo de regionalização em saúde.

Foi constatado que as comissões intergestores regional, potenciais ao fortalecimento das redes regionalizadas, possuem aspectos que dificultam a formação das redes de serviços de saúde, requerendo esforços para que aconteçam. A estruturação das redes tem possibilitado o acesso aos serviços de média e alta densidade tecnológica, principalmente para os municípios de pequeno porte da região de saúde, como tentativa para adequar as necessidades regionais com as possibilidades da gestão, favorecendo a regionalização solidária e cooperativa. 
Finalmente, a metodologia utilizada para o desenvolvimento desta pesquisa/investigação qualitativa possibilitou trazer à baila as dificuldades reais encontradas pela gestão em saúde para a consolidação do SUS na perspectiva da regionalização, evidenciando a necessidade da ampliação dos estudos voltados a essa temática que abordem as possibilidades e experiências relacionadas aos espaços colegiados de gestão possíveis de serem discutidas a partir da utilização de distintas técnicas de coleta e análise de dados/achados.

\section{Referências}

ASSIS, E. et al. Regionalização e Novos Rumos para o SUS: a experiência de um colegiado regional. Saúde e Sociedade, São Paulo, v. 18, n. 01, p. 17-21, 2009.

BAHIA. Comissão Intergestores Bipartite. Resolução CIB No 143 DE 09 de outubro de 2007. Diário Oficial do Estado da Bahia, Salvador, n.154, p. 186-188, out. 2007.

BAHIA. Comissão Intergestores Bipartite. Resolução CIB No 275 DE 15 de agosto de 2012. Diário Oficial do Estado da Bahia, Salvador, ago. 2012.

BARDIN, L. Análise de conteúdo. In: MINAYO, M.C.S. et al. Pesquisa Social: teoria, método e criatividade. 28. ed. Petrópolis - RJ; Editora Vozes, 2009.

BARRIOS, S.T.G. Micropolítica e gestão regionalizada da saúde: estudo de caso no colegiado de gestão da 4a região sanitária do Estado do Rio Grande do Sul.177 f. 2009. Dissertação (Mestrado em Enfermagem) - Universidade Federal de Santa Maria, Santa Maria, 2009.

BRASIL. Constituição Federal, de 05 de outubro de 1988.

BRASIL. Ministério da Saúde. Secretaria de Assistência à Saúde Departamento de Descentralização da Gestão da Assistência. Regionalização da Assistência à saúde: aprofundando a descentralização com equidade no acesso. Brasília, 2001.

BRASIL. Ministério da Saúde. Secretaria de Assistência à Saúde Departamento de Descentralização da Gestão da Assistência. Regionalização da Assistência à saúde: aprofundando a descentralização com equidade no acesso. Brasília, 2002.

BRASIL. Ministério da Saúde. Portaria n 399 de 22 de fevereiro de 2006. Divulga o Pacto pela Saúde 2006. Diário Oficial da União, Brasília, n. 39, p. 43, fev. $2006 a$.

BRASIL. Secretaria Executiva. Departamento de Apoio à Descentralização. Coordenação-Geral de Apoio à Gestão Descentralizada. Diretrizes operacionais dos Pactos pela Vida, em Defesa do SUS e de Gestão. Brasília. 2006b.

BRASIL. Ministério da Saúde. Portaria $n^{\circ} 2.691$ de 18 de outubro de 2007. Diário Oficial União, Brasília, n.242, p. 47, dez. 2007.

BRASIL. Ministério da Saúde. Secretaria de Atenção à Saúde, Diretoria de Articulação de Redes de Atenção à Saúde. Documento Base. Redes Regionalizadas de Atenção à Saúde: 
Contextos, Premissas, Diretrizes Gerais, Agenda Tripartite para Discussão de Propostas de Metodologia para Apoio à Implementação. Brasília, 2008.

BRASIL. Ministério da Saúde. Secretaria-Executiva. Departamento de Apoio à Gestão Descentralizada. Colegiado de Gestão Regional na Região de Saúde Intraestadual:

Orientações para organização e funcionamento. Brasília Série B. Série Pactos pela Saúde 2006, v. $10,2009$.

BRASIL. Ministério da Saúde. Decreto $n^{0} 7.508$ de 28 de junho de 2011: regulamentação da Lei no 8.080/90. Brasília: Ministério da Saúde, 2011a.

BRASIL. Ministério da Saúde. Portaria n ${ }^{\circ} 1.600$ de 07 de julho de 2011. Diário Oficial da União, Brasília, n. 130, p. 70, jul. 2011 b.

BRASIL. Ministério da Saúde. Portaria n 1.459 de 24 de junho de 2011. Diário Oficial da União, Brasília, jun. 2011c.

CECÍLIO, L.C.O. Colegiados de gestão em serviços de saúde: um estudo empírico. Cad. Saúde Pública, São Paulo, v.26, n.3, p. 557-566, mar. 2010.

DALTRO, E.F.M. A.; BARBOSA, D.S.J. Projeto SAMU Regional Reconvale: Exercitando a Regionalização Solidária. ENAPEGS, VI. Gestão social, Políticas públicas e território. Santo Antônio de Jesus - BA. 2012.

DELZIOVO, C.R. Colegiado de Gestão Regional Desafios e Perspectivas: Relato de Experiência. Saude. \& Transformação Social, Florianópolis-SC, v.3, n.1, p. 102-105, 2012.

DOURADO, D. A.; ELIAS, P. E. M. Regionalização e Dinâmica Política do Federalismo Sanitário Brasileiro. Revista Saúde Pública, São Paulo, v. 45, n. 1, p. 204-211, 2011.

DUARTE, R. Pesquisa qualitativa: reflexões sobre o trabalho de campo. Cadernos de Pesquisa, Rio de Janeiro-RJ, v. 5, n. 115, p.139-154, mar. 2002.

GASKELL, G. Entrevistas individuais e grupais. In: BAUER, M.W; GASKELL, G. Pesquisa Qualitativa com texto: imagem e som: um manual prático. 7. ed. Petrópolis-RJ: Editora Vozes, p. 64-89, 2008.

GIL, A.C. Como classificar as pesquisas? In: GIL, A. C. Como elaborar projetos de pesquisa. 4. ed. São Paulo-SP: Editora Atlas, 2002. p. 15-176

GOMES, R. Análise e Interpretação de dados de Pesquisa Qualitativa. In: MINAYO, M. C. S. Pesquisa Social: Teoria, Método e Criatividade. 29. ed. Petrópolis-RJ: Editora Vozes, 2010. p. $79-108$.

IANNI, A.M.Z. et al. Metrópole e região: dilemas da pactuação da saúde. O caso da Região Metropolitana da Baixada Santista. Cad. Saúde Pública, São Paulo, v. 28, n. 5, p. 925-934, maio. 2012.

KISHIMA, V.C.; ZANATTA, C.L.; JÚNIOR A.E. O Colegiado de Gestão Regional como estratégia para aprimorar as relações intergovernamentais e fortalecer o Sistema Único de Saúde. In: ENCONTRO DA ASSOCIAÇÃO NACIONAL DE PÓS-GRADUAÇÃO E PESQUISAS EM ADMINISTRAÇÃO, 36, 2012, Rio de Janeiro. Anais... Rio de Janeiro: ANPAD, 2012. p. 1-14. 
LAVRAS, C. Atenção primária à saúde e a organização de redes regionais de atenção à saúde no Brasil. Saúde soc., Campinas, v.20, n.4, p.867-874, 2011.

LIMA, L.D. et al. Descentralização e regionalização: dinâmica e condicionantes da implantação do Pacto pela Saúde no Brasil. Ciênc. saúde coletiva, Rio de Janeiro, v.17, n.7, p. 1903-1914, 2012 .

MANZINI, E. J. A entrevista na pesquisa social. Didática, São Paulo, v. 26/27, p. 149-158, 1991.

MENDES, E. V. As redes de atenção à saúde. 2. ed. Brasília: Organização Pan-Americana da Saúde, 2011.

MINAYO, M.C.S. O desafio do conhecimento: pesquisa qualitativa em saúde. 9. ed. São Paulo-SP: Editora Vozes, 2006.

MINAYO, M. C. S. et al. Pesquisa Social: teoria, método e criatividade. 28. ed. Petrópolis: Editora Vozes, 2009.

PAIVA, et al. Acesso e regionalização em saúde: análise de um serviço ambulatorial de média complexidade. Rev. APS, Juiz de Fora, v. 13, n. 1, p. S3-S14, 2010.

SANTOS, A. M.; GIOVANELLA, L. Governança regional: estratégias e disputas para gestão em saúde. Rev. Saúde Pública, São Paulo, v.48, n.4, p. 622-631, 2014.

SCHNEIDER, A. et al. Pacto pela saúde: possibilidade ou realidade? 2. ed. Passo Fundo: Centro de Educação e Assessoramento Popular/ CEAP, 2009.

SILVEIRA FILHO. et al. Ações da Comissão Intergestores Regional para gestão compartilhada de serviços especializados no Sistema Único de Saúde. Physis Revista de Saúde Coletiva, Rio de Janeiro, v.26, n.3, p. 853-878, 2016.

SOLLA. J. J. S. P. Avanços e limites da descentralização no SUS e o "Pacto de Gestão". Revista Baiana de Saúde Pública, Salvador, v. 30, n. 2, p. 332-348, jul. 2006.

SOUZA, M. R. N. S; SOUZA M. K. B. Regionalização em Saúde e Colegiados/Comissões de Gestão: dinâmica, contribuições, potencialidades e desafios. In: CONGRESSO IBERO AMERICANO EM INVESTIGAÇÃO QUALITATIVA, 6, 2017, Salamanca. Anais... Salamanca: Universidade Lusófona do Porto, 2017. p. 146-155.

VASCONCELOS, C. M. Notas sobre a crise nos hospitais universitários no Brasil. 2005. Disponível em: <http://www.denem.org.br/2005/arquivos/ok1121496462023.doc >. Acesso em: 02 set. 2013.

VIANA, A. L. D.; LIMA, L. D.; FERREIRA, M. P. Condicionantes estruturais da regionalização na saúde: tipologia dos Colegiados de Gestão Regional.Ciência Saúde Coletiva, Rio de Janeiro, v. 15, n. 5, p. 2317-2326, 2010.

Recebido em: 24 de março de 2018.

Aceito em: 03 de abril de 2018. 